EPiC Series in Language and Linguistics
Volume 2, 2017, Pages 325-334
Professional and Academic Discourse:
an Interdisciplinary Perspective

\title{
Exploring the Patterns of Verbal Agreement of Collective Noun-Headed Subjects in a Parsed Corpus of Present-Day English*
}

\author{
Yolanda Fernández-Pena \\ University of Vigo, Vigo, Spain \\ yolanda.fernandez@uvigo.es
}

\begin{abstract}
This study explores verbal agreement variation with collective noun-headed subjects taking plural of-dependents in a set of data retrieved from a parsed version of the corpus of Global Web-based English (GloWbE). The results show how syntactic distance between the subject and the verb (and also the complexity of the modifier(s) of the of-PP) reduces the influence that these plural of-PPs exert on the verb, thus lowering the rate of plural agreement.
\end{abstract}

\section{Introduction}

In this paper, I will first outline some basic concepts pertaining to verbal agreement with collective nouns in Section 2, and the main aims of this study as well as the methodological procedure applied in Section 3. In Section 4, I will present the data analysis, which covers two questions: regional variation and syntactic complexity. Finally, I will put forward the conclusions in Section 5.

\section{Variation in Verbal Agreement with Collective Nouns}

Collective noun-headed subjects, i.e. those which denote "a group of animates or inanimates" (e.g. committee, party, series, number), usually take singular or plural verbs according to whether the speaker focuses on the collectivity (1) or on its individuals (2) (Dekeyser 1975, 35fn1, 37; see also Biber et al. 1999: 188).

\footnotetext{
* This study has been funded by the Spanish Ministry of Science and Innovation and the European Regional Development Fund (grants no. FFI2013-44065-P, FFI2014-51873-REDT and FPU FPU13/01509), and the Autonomous Government of Galicia (Secretary General of Universities, grants no. GPC2014/060 and R2014/016). I would like to express my gratitude to Javier Pérez Guerra for his valuable comments on an earlier version of this paper. I am also grateful to Marianne Hundt, Hans M. Lehmann and Gerold Schneider for giving me access to the Dependency Bank interface and to David Tizón-Couto for his help and advice.
} 
1. the crowd of curious onlookers was so thick that the paramedics had trouble lifting the body from the ambulance. [GloWbE: w_tz_g03]

2. The crowd of delegates are eating all this up [GloWbE: w_gb_g18]

The plural of-dependents that often accompany some collective nouns such as crowd in (1) and (2) usually involve further complications for subject-verb agreement. In previous literature, these plural ofPPs have not been devoted sufficient attention and their role in agreement has been oversimplified and attributed to mere attraction effects (cf. Levin, 2001). However, as recent corpus-based studies have attested (see Fernández-Pena 2015, 2017), and as will also be shown in this paper, these of-dependents significantly interact with verbal agreement in Present-Day British and American English inasmuch as they reinforce the conceptual plurality inherent to the collective noun and thus favour a higher likelihood of plural verb number, as in (2) above. This preference for the plural verb number is especially noticeable in local syntactic domains but loses significance with increasing syntactic distance between the collective subject and the verb (see Section 4.2).

\section{Aims and Methodological Procedure}

Taking as a point of departure prior corpus-based studies on Present-Day English (Fernández-Pena, 2015 and 2017, using data from the British National Corpus or BNC and the Corpus of Contemporary American English or COCA), the research reported here aims at broadening the scope of such investigation by exploring verbal agreement with collective noun-based subjects in the so-called 'New Englishes', a topic with few antecedents in the literature (Hundt, 2006, 2009; Jantos 2010). This study thus seeks to find further data for British and American English as well as for other regional varieties so as to corroborate/refute my previous observations as regards syntactic complexity and to provide a wider picture on these constructions.

To this end, I have examined verbal agreement with complex collective-headed constructions ( $N_{C O L L}-O f-N_{P L}$ subjects) comprising:

a. a singular collective noun (23 different collective nouns - Biber et al. 1999: 249 and Huddleston and Pullum et al. 2002: 503 - and up to 3,000 hits per collective were considered),

b. a postmodifying of-PP with a plural noun,

c. an inflected verbal form.

The data were retrieved from a parsed version of GloWbE, a corpus comprising twenty different varieties of English, and using the syntax query of the Dependency Bank interface of the University of Zurich. ${ }^{\dagger}$ The parser ${ }^{\ddagger}$ identified over 32,000 examples of $N_{C O L L}-O f-N_{P L}$ subjects (reliability of $87 \%$ ) which, after the manual pruning, resulted in 8,742 valid instances.

\section{Data Analysis}

In this section, I will present the results of the corpus-based study. First, I will comment on the issue of regional variation. The remainder of the section will be devoted to discuss how syntactic complexity affects verbal agreement in the constructions under study.

\footnotetext{
${ }^{\dagger}$ For further information: http://www.es.uzh.ch/services/corpling.html

‡ The Pro3Gres Parser: see https://files.ifi.uzh.ch/cl/gschneid/parser/
} 


\subsection{Regional Variation}

In the data obtained from GloWbE we observe that of-PPs still exert some influence on verb number, but the results differ significantly from those in BNC and COCA, where plural agreement was considerably higher ( $53.28 \%$ vs. $65.42 \%$, respectively; $\left.\chi^{2}(1)=181.4, p<.0001\right)$.

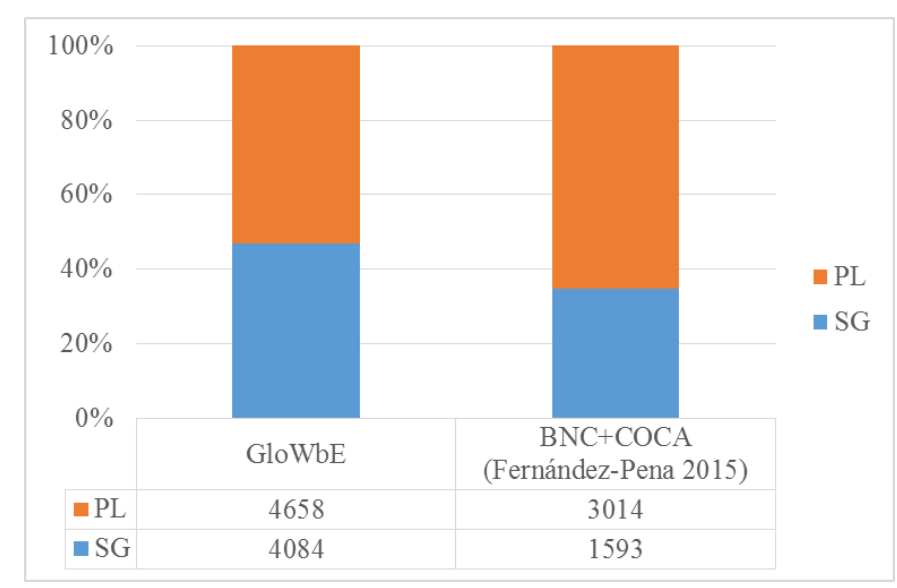

Figure 1. Verbal agreement in GloWbE vs. BNC+COCA

As commented earlier, GloWbE comprises twenty different regional varieties of English. Their heterogeneity and the potential influence of substrate (native) languages other than English are expected to be influencing these results. In fact, statistical significance is obtained for the variable 'regional variety' in the results obtained (ANOVA: $\chi^{2}(19)=99.47, \mathrm{p}<.0001$ ). The preliminary analysis presented in Table 1 already reveals the substantial variation of the patterns of agreement of these varieties.

\begin{tabular}{llll}
\hline Regional Variety & Singular verb & Plural verb & Total \\
\hline Jamaica & $59(33.15 \%)$ & $119(66.85 \%)$ & 178 \\
Nigeria & $59(35.98 \%)$ & $105(64.02 \%)$ & 164 \\
Ireland & $178(36.03 \%)$ & $316(63.97 \%)$ & 494 \\
Tanzania & $71(39.44 \%)$ & $109(60.56 \%)$ & 180 \\
Great Britain & $795(42.74 \%)$ & $1,065(57.26 \%)$ & 1,860 \\
Sri Lanka & $106(43.98 \%)$ & $135(56.02 \%)$ & 241 \\
Kenya & $103(44.59 \%)$ & $128(55.41 \%)$ & 231 \\
Pakistan & $103(44.59 \%)$ & $128(55.41 \%)$ & 231 \\
Ghana & $76(44.71 \%)$ & $94(55.29 \%)$ & 170 \\
Canada & $291(47.63 \%)$ & $320(52.37 \%)$ & 611 \\
Australia & $228(48.10 \%)$ & $246(51.90 \%)$ & 474 \\
South Africa & $124(48.63 \%)$ & $131(51.37 \%)$ & 255 \\
New Zealand & $206(49.16 \%)$ & $213(50.84 \%)$ & 419 \\
Singapore & $92(49.73 \%)$ & $93(50.27 \%)$ & 185 \\
Malaysia & $85(50.60 \%)$ & $83(49.40 \%)$ & 168 \\
India & $243(50.84 \%)$ & $235(49.16 \%)$ & 478 \\
United States & $911(52.18 \%)$ & $835(47.82 \%)$ & 1,746 \\
Bangladesh & $133(52.78 \%)$ & $119(47.22 \%)$ & 252 \\
Philippines & $89(53.29 \%)$ & $78(46.71 \%)$ & 167 \\
Hong Kong & $132(55.46 \%)$ & $106(44.54 \%)$ & 238 \\
\hline
\end{tabular}

Table 1. Verbal agreement in the twenty varieties of English in GloWbE 
Table 1 evinces remarkable differences among the varieties, with only nine favouring plural agreement in more than $55 \%$ of the cases while the rest have proportions lower than $53 \%$ or even show a preference for singular verb number. Pending a more fine-grained analysis, it seems quite evident that this variability can be responsible for the general rate of agreement in the corpus as a whole.

Given these data and for the sake of simplicity, in the current section I will restrict the scope of the study to only the inner (i.e. native, see Kachru 1985) varieties of the corpus: Irish, British, Canadian, Australian, New Zealand and American English. This limitation allows us to avoid any possible interference of substrate languages in the results provided, yet it does not guarantee a more homogeneous panorama. In fact, as already illustrated in Table 1 and repeated in Table 2 for the sake of clarity, even within this set of six varieties we still observe significant variation.

\begin{tabular}{llll}
\hline Regional Variety & Singular verb & Plural verb & Total \\
\hline Ireland & $178(36.03 \%)$ & $316(63.97 \%)$ & 494 \\
Great Britain & $795(42.74 \%)$ & $1,065(57.26 \%)$ & 1,860 \\
Canada & $291(47.63 \%)$ & $320(52.37 \%)$ & 611 \\
Australia & $228(48.10 \%)$ & $246(51.90 \%)$ & 474 \\
New Zealand & $206(49.16 \%)$ & $213(50.84 \%)$ & 419 \\
United States & $911(52.18 \%)$ & $835(47.82 \%)$ & 1,746 \\
TOTAL & 2,609 & 2,995 & 5,604 \\
\hline
\end{tabular}

Table 2. Verbal agreement in the inner varieties in GloWbE

As presented in Table 2, these varieties show three different trends: Irish and British English favouring plural agreement, the US showing the opposite tendency and, finally, the other three varieties with quite even figures for both numbers. This (to a certain extent) geographical classification is statistically confirmed after carrying out an association plot.

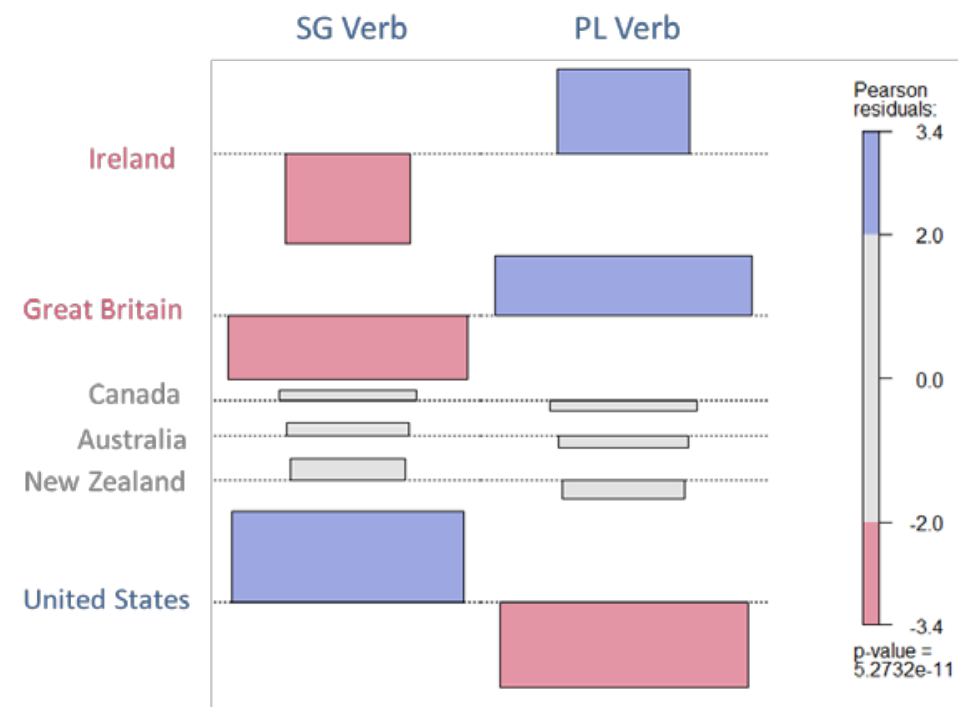

Figure 2. Pearson residuals in the inner varieties in GloWbE

As Figure 2 evinces, only the preference for plural agreement in Ireland and Great Britain and the figures for singular agreement in the US reach significance, those of Australia, New Zealand and Canada are not relevant in this regard. 
Concerning the varieties of English considered in Fernández-Pena (2015, 2017), i.e. British and American English, it must be noted that very few statistically significant differences were found between the figures from BNC and those from COCA. These observations on regional variation were unexpected, as prior literature had largely attested the two aforementioned marked and divergent tendencies observed in the data from GloWbE (see Bauer 1994; Levin 2001; Depraetere 2003; Algeo 2006; or Trudgill and Hannah 2008).

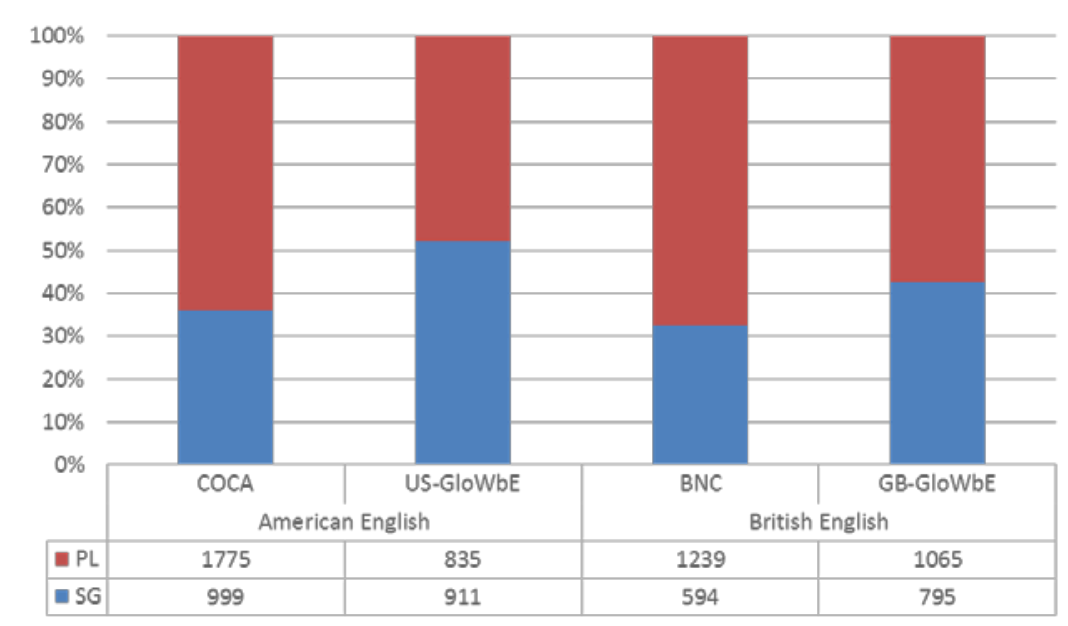

Figure 3. Verbal agreement in American and British English in COCA, BNC and GloWbE

Figure 3 evinces the aforementioned differences. Hence, in both the American and the British component of GloWbE we observe significantly lower proportions of plural agreement than those in COCA and BNC (i.e. $47.82 \%$ and $57.26 \%$ in GloWbE vs. $63.99 \%$ in COCA and $67.59 \%$; $\chi^{2}(1)$, $\mathrm{p}<.0001)$. Pending further examination, the evidence seems to suggest that such divergence may stem from the very different genre and registers of these three corpora: BNC and COCA comprising more formal texts, ranging from academic texts to fiction, popular magazines or newspapers, ${ }^{\S}$ whereas GloWbE contains only blogs and webpages.

\subsection{Syntactic Complexity}

As already commented, the patterns of verbal agreement of collective nouns tend to vary according to the holistic or individualistic (i.e. singular vs. plural) conceptualisation of the group. Earlier investigations on this topic have found, however, that only the latter prevails over distance. In fact, in his study Levin (2001: 93) attests that

[t]he probability of the [verbal] target agreeing with the syntactic form of the controller decreases

with distance in words [since] distance decreases the focus on the grammatical number of the controllers, and the referents of the controller become more prominent.

In other words, and drawing from Corbett's (1979) Agreement Hierarchy, Levin's (2001) investigation explains that syntactic boundaries constrain our short-term memory to the extent that the formal characteristics of the collective noun are less likely to be activated over distance. As a result, only the semantic properties (i.e. the plurality) of the collective prevail and eventually trigger higher proportions of plural verb number. The $N_{C O L L}-O f-N_{P L}$ constructions under scrutiny here comprise both a semantically plural collective noun and a morphologically and semantically plural noun within the ofPP. Contrary to expectations, Fernández-Pena $(2015,2017)$ demonstrated that $N_{C O L L}-O f-N_{P L}$ subjects do

\footnotetext{
$\S$ Only the written components of BNC and COCA have been considered.
} 
not take a higher rate of plural verbal patterns but that, by contrast, increasing syntactic distance and complexity significantly lowers their proportions of plural verb number.

The data from GloWbE further corroborate my prior observations for the four syntactic configurations of the of-PP examined here:

3. of + bare NP: your little band [of fanatics] are looking smaller and smaller [GloWbE: w_nz_b10]

4. of + premodifier + NP: a gang [of armed men] are reported to have raped five women [GloWbE: w_jm_b04]

5. of + bare NP + postmodifier: A group [of students from Jamaica College] have declared that adults are failing their children [GloWbE: $\left.\mathbf{w} \_j \mathrm{~m} \_g 10\right]$

6. of + premodifier + NP + postmodifier: a large number [of spiritual children in this country] are concerned about their future [GloWbE: w_pk_g06]

Figure 4 and Figure 5 below present the percentages of agreement for these four types of constituent structure of the of-PP in American and British English in GloWbE, respectively. In both cases, when agreement is established locally, i.e. with no intervening material between the subject and the verb, as in (3) and (4) above, plural verb number is significantly high: 47.94\% and 50.30\% in American English vs. $55.57 \%$ and $65.36 \%$ in British English.

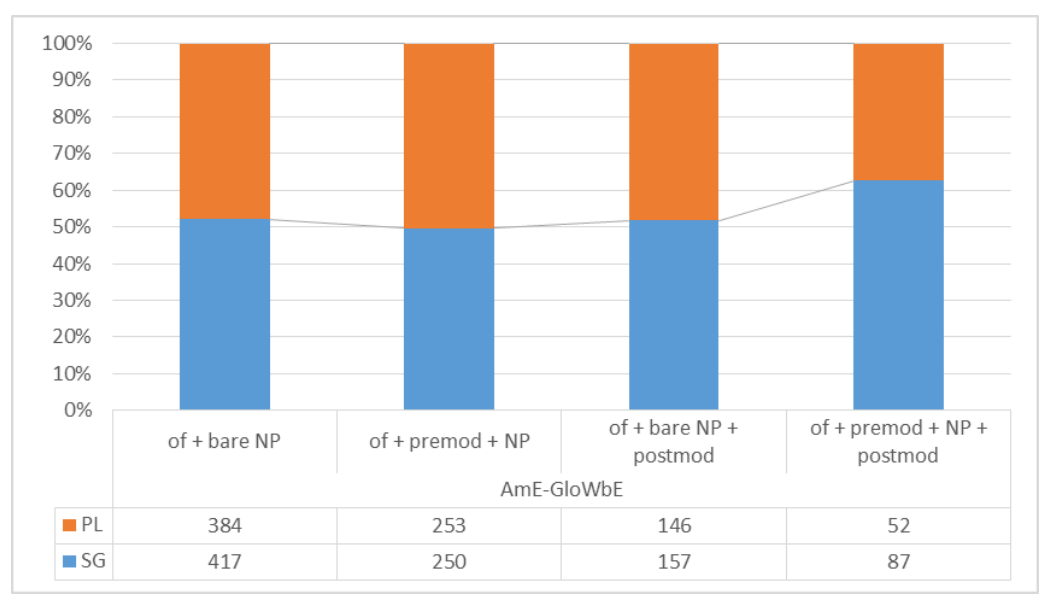

Figure 4. Verbal agreement in bare, premodified and/or postmodified of-dependents in American English in GloWbE 


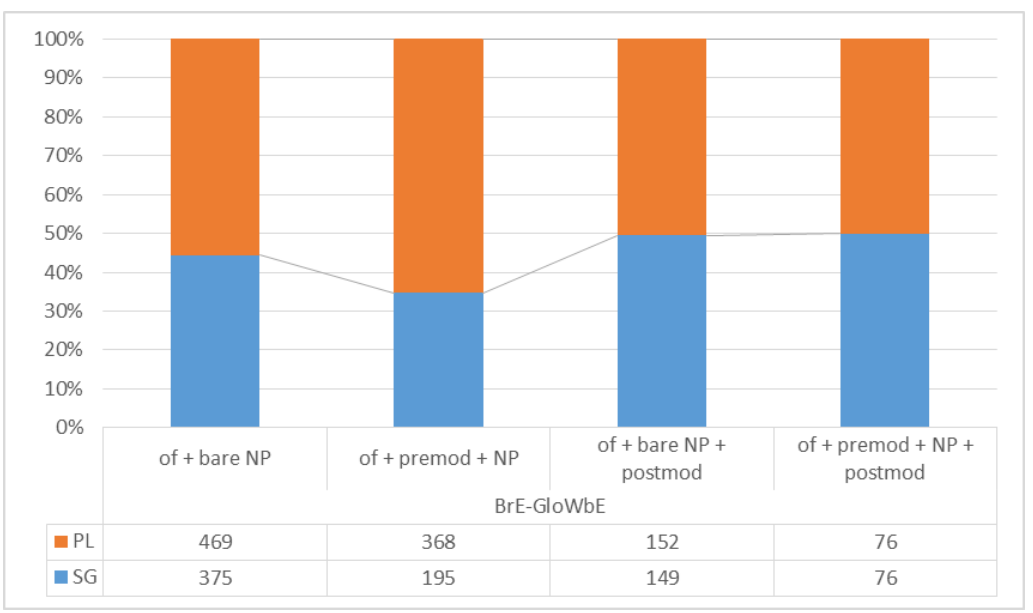

Figure 5. Verbal agreement in bare, premodified and/or postmodified of-dependents in British English in GloWbE

As postmodifiers enter the picture, and thus syntactic distance between the subject and the verb increases (see (5) and (6) above), plural verb number experiments a decrease in both varieties of English. In fact, postmodified structures have a lower rate of plural agreement than non-postmodified structures (i.e. 48.18\% and 50.50\% in American and British English, respectively), a decrease which is even more noticeable in the most complex structure: of + premodifier + NP + postmodifier (i.e. $37.41 \%$ in American English $-\chi^{2}(1)=4.87, \mathrm{p}<.0001-$ vs. $50.00 \%$ in British English).

In order to determine further factors influencing this decrease of plural verb number over distance, I have also investigated the typology of the postnominal modifiers (PNMs). These of-PPs are most frequently modified by another prepositional phrase (about $47 \%$ ) or a non-finite clause (i.e. TP; $21 \%$ ), with relative clauses and noun phrases showing a lower incidence (about $16 \%$ and $7 \%$, respectively). As regards their constituent structure, these PNMs can be classified according to their non-clausal - (7) and (8) - or clausal - (9) and (10) - status.

7. PP: the majority of people in this country have finally accepted [GloWbE: w_gb_g14]

8. NP: A band of male lions, often brothers, have a range which they mark patrol and defend. [GloWbE: w_tz_g10]

9. TP: The vast majority of kiwis living in Australia don't have enough points to qualify for PR [GloWbE: w_nz_g07]

10. REL CL: a group of connected rooms, which are built as living quarters, have a separate entrance [GLoWbE:w_gh_g07]

It must be noted that collective-headed subjects containing clausal PNMs (i.e. TPs and REL CLs) are assumed to be syntactically more complex, the main reason being the fact that they contain a verbal element and therefore may take a subcategorisation pattern (Berlage 2014: 41-42; see also Frazier 1985; Smith 1988; Ferreira 1991; Wasow 1997; Yaruss 1999 or Gibson 2000). In line with the literature, being more complex should imply taking a higher rate of plural verb number. 


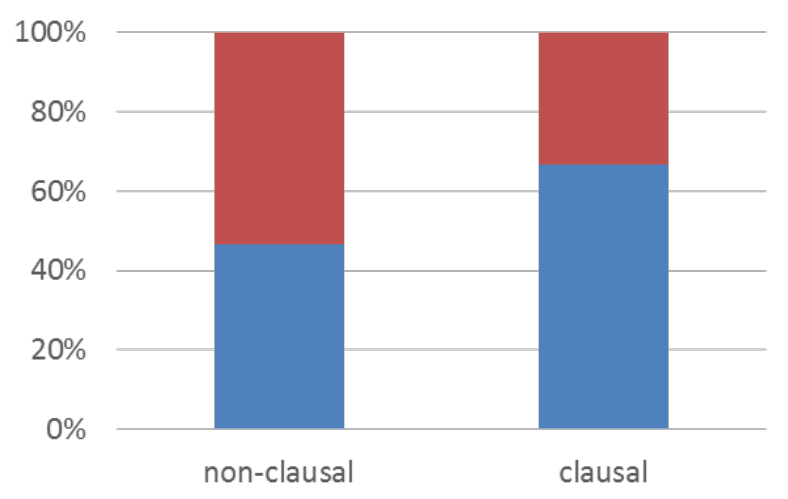

Figure 6. Verbal agreement with each type of PNM in American English

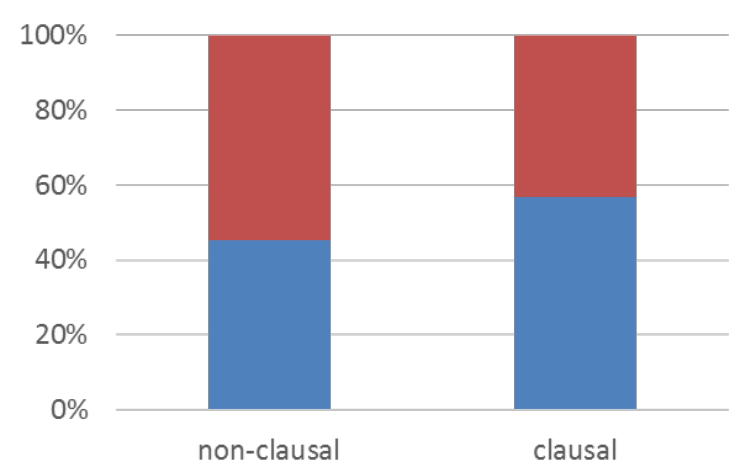

Figure 7. Verbal agreement with each type of PNM in American English

The analysis of their corresponding patterns of agreement, however, confirms that complexity does not correlate with a higher rate of plural agreement in the constructions under scrutiny since clausal PNMs take a significantly lower rate of plural agreement in both varieties $\left(\chi^{2}(1), \mathrm{p}<.0001\right)$. This finding suggests that the preference for the use of the (unmarked) singular number could be a resource to ease the cognitive processing of these complex $N_{C O L L}-O f-N_{P L}$ constructions. Neither conclusive results nor support has been found yet and thus this issue calls for further consideration.

\section{Conclusions}

The research reported in this paper has demonstrated that $N_{C O L L}-o f-N_{P L}$ subjects show significant variation in verbal agreement in Present-Day British and American English as well as in other regional varieties.

As for syntactic complexity, the results have yielded further support to my prior observations and, in turn, have further refuted earlier literature on collective nouns. The data have illustrated how in these particular constructions syntactic distance and complexity correlate with progressively lower rates of plural agreement in both British and American English. Despite the significance of this finding, it remains to be seen the effects of distance on the other regional varieties in GloWbE. 


\section{References}

Algeo, J. (2006). British or American English? A Handbook of Word and Grammar Patterns. Cambridge: Cambridge University Press.

Bauer, L. (1994). Watching English change. New York: Longman.

Berlage, E. (2014). Noun Phrase Complexity in English. Cambridge: Cambridge University Press.

Biber, D., Johansson, S., Leech, G., Conrad, S., Finegan, E. (1999). Longman Grammar of Spoken and Written English. London: Longman.

BNC = British National Corpus <http://bncweb.lancs.ac.uk/bncwebSignup/user/login.php>

COCA = Corpus of Contemporary American English $<$ http://corpus.byu.edu/coca $>$

Corbett, G. G. (1979). “The agreement hierarchy”. Journal of English Linguistics 15, 203-224.

Dekeyser, X. (1975). Number and Case Relations in $19^{\text {th }} \mathrm{c}$. British English: A Comparative Study of Grammar and Usage. Belgium: De Nederlandsche Boekhandel.

Depraetere, I. (2003). "On verbal concord with collective nouns in British English”. English Language and Linguistics 7(1), 85-127.

Fernández-Pena, Y. (2015). "Verbal agreement with collective noun-based constructions: Syntactic and lexical implications of of-dependents”. In A. Lázaro Lafuente, M. D. Porto Requejo (eds.), English and American Studies in Spain: New Developments and Trends. Alcalá de Henares: University of Alcalá, 206-217.

Fernández-Pena, Y. (2017). "Patterns of verbal agreement with collective nouns taking plural ofdependents: A corpus-based analysis on syntactic distance”. To be published in Corpora 12(2).

Ferreira, F. (1991). "Effects of length and syntactic complexity on initiation times for prepared sentences". Journal of memory and Language 30(2): 210-233.

Frazier, L. (1985) "Syntactic complexity”. In D. R. Dowty, L. Karttunen, A. M. Zwicky (eds.), Natural Language Parsing. Cambridge: Cambridge University Press, 129-189.

Gibson, E. (2000). "The Dependency Locality Theory: A distance-based theory of linguistic complexity”. In A. Marantz, Y. Miyashita, W. O’Neil (eds.), Image, Language, Brain. Papers from the First Mind Articulation Symposium. Cambridge, Mass.: MIT, 95-126.

GloWbE = Corpus of Global Web-based English (Dependency Bank 2.0; 2010-2013 H. M. Lehmann and G. Schneider; University of Zurich) < http://www.es.uzh.ch/services/corpling.html>

Huddleston, R., Pullum, G. K. et al. (2002). The Cambridge Grammar of the English Language. Cambridge: Cambridge University Press.

Hundt, M. (2006). "The committee has/have decided...: On concord patterns with collective nouns in inner- and outer-varieties of English”. Journal of English Linguistics 34(3): 206-232.

Hundt, M. (2009). “Concord with collective nouns in Australian and New Zealand English”. In P. Peters, P. Collins, A. Smith (eds.), Comparative Studies in Australian and New Zealand English: Grammar and beyond. Amsterdam: John Benjamins, 207-224.

Jantos, S. (2010). “Agreement in educated Jamaican English: A corpus-based study of spoken usage in ICE-Jamaica”. In H. Dorgeloh, A. Wanner (eds.), Syntactic Variation and Genre. Berlin: Mouton de Gruyter, 305-331.

Kachru, B. B. (1985). "Standards, codification, and sociolinguistic realism: The English language in the outer circle". In R. Quirk, H. Widdowson (eds.), English in the world: Teaching and learning of Language and Literature. Cambridge: Cambridge University Press, 11-30.

Levin, M. (2001). Agreement with Collective Nouns in English. Lund: Lund Studies in English.

Smith, C. S. (1988). "Factors of linguistic complexity and performance". In A. Davison, G. M. Green (eds.), Linguistic Complexity and Text Comprehension: Readability Issues Reconsidered. Hillsdale, NJ: Lawrence Erlbaum, 247-79.

Trudgill, P., Hannah, J. (2008). International English. A Guide to Varieties of Standard English. London: Hodder Education. 
Wasow, T. (1997). "Remarks on grammatical weight”. Language Variation and Change 9 (1): 81105.

Yaruss, J. S. (1999). “Utterance length, syntactic complexity, and childhood stuttering”. Journal of Speech, Language, and Hearing Research 42(2): 329-344. 